present day. Look alone at the assertions within the last few years as to the cause and proper treatment of plague, cholera, yellow, typhus, and typhoid fevers, and other epidemics affecting man and animal. See even how it has influenced, and not unfrequently led to hasty and injurious legislation on such subjects. It is the foundation for most of the evidence upon which every empiric relies, and vaunts and parades his success as infallible. He has dore a certain thing to a certain part; it has become well ; ergo, his remedy has cured the disease. If such be correct, every homœopath has good ground for his assumed success. Recollect the evidence and cases of success which lately were brought forward in support of the asserted cure of cancerous tumours by the injection of acetic acid. Yet who now believes in the truth of the doctrine? Sir J. Simpson, Drs. Pirrie, Keith, Fiddes, and others, have brought forward cases quite as numerous, and undoubtedly quite as true, in proof of their declaration that the use of fibrous material as ligatures upon arteries is the true cause of all those disastrous consequences which so often follow operations, as have Mr. Lister and others in proof of their assertion, that it is the introduction of septic germs which does all the mischief. They have performed large, important, and dangerous operations of all kinds, merely substituting acupressure in closing the arteries for threads. They have never dreamed of applying antiseptic treatment for the destruction of septic germs, to which, by discarding all dressings, they allow the freest entrance to the wounded part, yet they have reported such a succession of marvellous cures as have fallen to the lot of few surgeons. Now, will Mr. Lister allow that their success was dependent upon acupressure alone? Setons have been used in surgery from time immemorial, and rowels still are employed in veterinary surgery, not only in the cure of abscesses, sinuses, and fistulæ, but to establish a drain in many external and internal complaints. M. Chassaignac has found many followers all the world over, in the use of drainage-tubes, made of vulcanised India-rubber, having plenty of holes stamped in them to render them still more patulous, in the treatment of recent abscesses, suppurating joints, and even effusions into the thoracic cavities; cures without number being reported as the happy result of thus affording a broad, direct, and easy road, with food by the way, for the free ingress of septic germs into all these varied cavities. Yet, surely, it can hardly be affirmed, if this treatment and the cures, as is stoutly declared, stand in the relation of cause and effect, that the antiseptic treatment and its cures also do so. If the one which acts by keeping the discharge in, and the exclusion and destruction of the germs, be true; the other, which acts by not only letting the discharges out, but the germs freely in, cannot also be true. Taken as sequents, the reported cures in both may be true, but regarded as consequences this is impossible.

That wounds, whether simply incised or lacerated and contused, often do well when dressed with carbolic acid, is perfectly true; but that they do better than wounds differently treated, I deny. It is useless to bring forward cases, and compare them with other cases, where the circumstances are altogether different. In private practice, as well as in large hospitals, especially in the latter, circumstances so vary, that to decide by a name alone is worse than useless. Every surgeon knows that, besides the individual varieties of age, constitution, condition, habits of life, the mode of receiving the injury or disease, there is a general law affecting all. At one time, all his operations do well; he hardly loses a case, whatever the operation may be; and at the same time all wounds heal quickly and well, without suppuration; or, if pus do form, it is limited, and is laudable: while, at another time, precisely similar cases do as badly, so that even very trivial wounds and operations are followed by death.* In our infirmary, a reference to the records of operations will show this difference in a striking manner; and everybody also knows quite well that at such times certain erysipeloid diseases are prevalent in the district, and that patients without wounds will fall into a bad condition, and not unfrequently exhibit * In the General Infirmary at Leeds, from May 1st to October 31 st, 1865 , out of
100 recorded operations, there were 21 deaths. In the following six months, Nov. 1865 to May 1866 , out of 118 operations, there were 23 deaths. From June to end of Nov. 1866, there were only Io deaths out of II 5 operations: while from October Ist, I868, to end of March, 1869 , out of 140 operations of all kinds, not, however, including the trivial, there were only six deaths; and, in the last three months of the period, only one death is recorded. In each of the periods, there was no material variation in the number of operations, and none, so far as I can ascertain, in the nature or gravity of the cases, and yet in the last six months the deaths are not quite $I$ in every 23 operations, while in the first the deaths amounted to over I in every 5 ; in the next six months to nearly as many; and in the six months from June to Novemthe next six months to nearly as many; and in the six months from June to Novem-
ber 1866 , the rate sunk to $\mathrm{I}$ in 12 . Seeing the number of patients in the hospital ber 1866 , the rate sunk to $\mathrm{I}$ in $\mathbf{I 2}$. Seeing the number of patients in the hospital
was the same in each period, there surely must have been some potent unseen cause influencing the result ; mere "hospitalism" will not account for it. In the last period, when there was the largest number of operations and the greatest crowding, period, when there was the largest number of operations and the greatest crowding,
the fatality was the least. Moreover, the last months of the hospital, which had been above a hundred years in use, were far more healthy than many periods which had occurred during its long occupation. Only operations of some magnitude are similar constitutional symptoms. There are undoubtedly phases of unhealthy atmospheric (or, I would rather suppose, telluric) influences, which, in spite of every known hygienic precaution, will make their influence most grievously felt. Hospitals have not unfrequently had to be wholly or in part temporarily closed from this cause. Therefore, to get at a fair comparison of the results of any particular treatment, the same class of cases should be treated at the same time and place. This I have carried out. During the last three years, since "the antiseptic treatment" has been in vogue, I have not allowed one of my patients to be treated with carbolic acid; while my colleagues have very extensively employed it, and I may say, at least at one time, possessing the full amount of faith necessary for securing success, fairly tried it. The result is, that my cases without it are as good as theirs with it. They have had some capital cases with it; but I am confident I am not in the least overstating facts, when I declare that for every successful case with it I can show one as good without it. This I consider to be a fair comparison, as the class of cases and other circumstances have been identical. Had I during this time found their success with the antiseptic treatment was greater than mine without it, I should gladly have availed myself of it; but I did not. On the other hand, as an additional proof that it has not been so, it may be mentioned that lately the omission of it, even in large operations, has been more and more frequent, until now its employment has become the exception, instead of the rule; which, had any marked benefit resulted from its use, most certainly would not have happened. Had carefully covering the cut surfaces with carbolic acid yielded great benefit, we should not have witnessed many large stumps left entirely exposed to the air, without any covering whatever upon them. That the two plans are wide as the poles asunder, is obvious to every one. If freely exposed stumps heal up readily and well, it must be at once apparent that those which do so when most elaborately swathed in carbolised wrappings, do so rather in spite of, than as a consequence of, the treatment.

One word more, and 1 have done. I have spoken plainly on the antiseptic treatment, because I have felt decidedly. Let me, however, not be misunderstood. I have no other object in view than the advance of our profession. I willingly pay deference to, and acknowledge with thanks as warm and as cordial as those who have believed and adopted the antiseptic treatment, what good has been done, and I trust will still be done, by some of those who have been the most decided advocates of the method. To them I would say, in the words which Shakespeare puts into the mouth of Brutus, when speaking in the Capitol to the Roman people over the dead body of Cæsar, "If there be any in this assembly, any dear friend of Cæsar's, to him I say that Brutus's love to Cæsar was no less than his. If then that friend demand why Brutus rose against Cæsar, this is my answer: Not that I loved Cæsar less, but that I loved Rome more." So would I say, not that I value their works and labours less, but that I value surgical science more. When I believe doctrines and practice to be true, I venture to acknowledge their value; but when I am convinced that they are wrong and injurious, I presume to say so.

[Since the reading of this Address, Mr. A. Prichard of Bristol has informed me that the operation of removing the entire eye-ball, instead of the anterior half of it, only originated with him, and not with Dr. O'Ferrall, to whom it is so often attributed.-T. N.]

\section{A CASE OF EPITHELIOMA OF THE LARYNX.}

\section{By Thomas Cole, M.D.Lond., Bath.}

A FINE boy, aged 5, was placed under my care in Jantuary I869, for laryngeal dyspnœa and a spasmodic barking cough. Otherwise, he was in good health, and seemed remarkably strong. He had no pain, nor expectoration. At one year of age, the breathing was observed to be rather difficult; and it became more and more so till I saw him. At four years of age, he fell into the river, and shortly afterwards the cough commenced. This, I think, was merely a coincidence. I was suspicious: of some kind of growth in the larynx, and cautioned the parents that the poor child might die suddenly. He would submit to no examination. Bromide of potassium was given for a month, with marked relief from the dyspnœa. On March 3 rd, the boy died almost instantaneously. The larynx, on post mortcm examination, was found to contain two large yellowish-white growths, each occupying one of the ventricles, and obscuring the vocal cords. The right tumour was as large as a horse-bean; the left, as a hazel-nut. The latter was somewhat hollowed out by the pressure of the former. There was a third smaller growth behind the left one. It seemed that no air could have entered the trachea, except by a very small passage left between the anterior surfaces of the tumours and the pomum Adami. Microscopically, the tumours proved to be good examples of epithelioma. Dr. Martyn of Clifton, who 